\title{
ARTIKELEN
}

\section{De cultuur van honoursstudenten en de mogelijke invloed op de reguliere studiecultuur}

\author{
Lammert Tiesinga \& Marca Wolfensberger ${ }^{*}$
}

Excellentie en studiecultuur staan in het hoger onderwijsbeleid al geruime tijd hoog op de agenda. Dit artikel gaat nader in op cultuuraspecten van het onderwijs en wil een aanzet leveren voor een meer systematisch denkkader over cultuurverandering in het hoger onderwijs. Leidende vragen zijn: wat kenmerkt de cultuur van honoursstudenten, waarin verschilt deze van de reguliere studiecultuur en wat is de mogelijke invloed van honourscultuur op de reguliere studiecultuur? Om die vragen goed te kunnen beantwoorden, wordt eerst theorie behandeld over een aantal voorafgaande vragen: wat is cultuur, schoolcultuur en studiecultuur? Kun je cultuurverandering in het hoger onderwijs tot stand brengen en excellentie stimuleren? Bevindingen uit onderzoek op basis van interviews van honoursstudenten en honoursdocenten van de Hanzehogeschool Groningen worden gepresenteerd, waarin vier elementen van honourscultuur naar voren komen. Verschillen tussen honoursstudenten en reguliere studenten komen aan de orde, alsmede de interactie tussen honoursstudenten en de omgeving buiten hun honourscommunity. Conclusies zijn dat er inderdaad sprake is van een honourscultuur die zich onderscheidt van de reguliere studiecultuur. Honoursstudenten zijn gedreven en ervaren hun honourscommunity als zeer stimulerend. Tot op zekere hoogte is er sprake van botsende culturen. De cultuur van honoursstudenten kan een stimulans zijn voor cultuurverandering, maar er zijn ook aspecten van cultuur die uitstralingseffecten kunnen belemmeren.

\section{Inleiding}

Achtereenvolgende regeringen hebben Nederland willen toerusten voor een positie in de voorhoede van kenniseconomieën (Ministerie van OCW, 2007, 2011). Als toekomstbeeld voor 2025 schetste de minister van OCW in de Strategische Agenda (Ministerie van OCW, 2011, p. 5) een studiecultuur aan hogescholen en universiteiten die zich kenmerkt door "uitdaging, presteren en het maximale uit je studie en je vermogens halen. De lat ligt hoger en de student die daar niet overheen kan springen, zal zijn ambities moeten bijstellen". Het Siriusprogramma zorgde voor grote investeringen in de ontwikkeling van excellentieprogramma's en uitdagend onderwijs. Een belangrijk doel in het verlengde van het rijksbeleid

* $\quad$ Drs. L. Tiesinga (1.tiesinga@pl.hanze.nl) is werkzaam bij het Hanze Honours College en tevens als onderzoeker bij het lectoraat Excellentie in Hoger Onderwijs en Samenleving. Dr. M.V.C. Wolfensberger (m.v.c.wolfensberger@pl.hanze.nl) is werkzaam bij de faculteit Geowetenschappen, Universiteit Utrecht en als lector aan de Hanzehogeschool Groningen. 
was een cultuurverandering teweeg te brengen in de richting van excellentie en een ambitieuze studiecultuur. Maar wat is cultuur, schoolcultuur of studiecultuur? En is cultuur veranderbaar? In dit artikel komen allereerst deze vragen aan de orde, om een antwoord te kunnen geven op drie centrale vragen: wat kenmerkt de cultuur van honoursstudenten, waarin verschilt deze van de reguliere studiecultuur en wat is de mogelijke invloed op de reguliere studiecultuur?

\section{Wat is cultuur?}

Cultuur is een veelgebruikt, maar ook uiteenlopend gedefinieerd begrip. Deal en Peterson (2009, p. 7) laten een aantal definities de revue passeren, bijvoorbeeld de definitie van Bower (1966) en van Deal en Kennedy (1982). Bower omschrijft cultuur als "the way we do things around here". Deal en Kennedy leggen de nadruk op het samenbindende karakter van cultuur en definiëren cultuur als "the shared beliefs that closely knit a community together". Cultuur omvat ook een patroon van normen, opvattingen en verwachtingen waaraan men zich conformeert (O’Reilly, 1989). Hofstede, Hofstede en Minkov (2011) spreken van mentale programmering of mentale software. Door opvoeding en socialisatie binnen een cultuur wordt het gedrag van een mens tot op zekere hoogte voorspelbaar.

Veelal wordt cultuur verbeeld als schillen van een ui, waarbij een onderscheid wordt gemaakt tussen waarden en grondbeginselen, die de kern vormen van de cultuur, en praktijken (rituelen, helden en symbolen), die de schillen vormen rond de kern (Boonstra, 2011; Hofstede, Hofstede, \& Minkov, 2011; Sanders \& Nueijen, 1999). Waarden zijn moeilijker te veranderen dan praktijken, omdat de meest fundamentele waarden tegen de tijd dat een kind tien jaar is mentaal al behoorlijk vastliggen. Deze vaststelling sluit aan bij studies die laten zien dat scholing en training van docenten in nieuwe werkwijzen moeizaam aanslaan als deze sterk afwijken van hun individuele waarden en opvattingen (zie o.a. Postareff, Lindblom-Ylänne, \& Nevgi 2007; Stes, Coertjens, \& Van Petegem 2010). Waarden overstijgen de grenzen van een organisatie en zijn niet eenvoudig te 'managen' (Harris \& Ogbanna, 1999). Ook is cultuur zelden eenduidig, wat het 'managen' complex maakt: binnen een organisatie kan sprake zijn van een tamelijk homogene, dominante cultuur, maar er kunnen ook subculturen bestaan of de cultuur kan in verschillende opzichten gefragmenteerd zijn (Martin, 2004).

\section{Schoolcultuur en studiecultuur}

Ook een onderwijsinstelling is een organisatie waarvan de leden een gemeenschap vormen met een bepaalde cultuur of subcultuur. Schoolcultuur is in navolging van Hudley en Daoud (2008) te definiëren als een verzameling van variabele, losjes georganiseerde gehelen van betekenissen (opvattingen, waarden, doelen) die van invloed zijn op de inzichten, gedragingen, verwachtingen, sociale normen en wijzen van communicatie van de groepsleden binnen een specifieke culturele 'niche' van de school waarvan men dagelijks deel uitmaakt (p. 188, eigen vertaling). Stu- 
diecultuur is in aansluiting bij deze definitie te beschouwen als een specifieke culturele 'niche' van studenten binnen de schoolcultuur, met waarden, opvattingen, verwachtingen en gedragingen die zijn gerelateerd aan het studeren. Een studiecultuur kan bijvoorbeeld gericht zijn op uitdaging, presteren en het maximale uit je studie en je vermogens halen. Begrippen als 'cultuur van excellentie' en 'ambitieuze studiecultuur' geven een specifieke invulling aan schoolcultuur en studiecultuur. Ze zijn te beschouwen als waarden, waaraan opvattingen, verwachtingen en gedragingen verbonden zijn.

\section{Stimuleren van excellentie}

Cultuurverandering in dit artikel betreft met name het stimuleren van excellentie en ambitie. Het stimuleren van excellentie gaat gepaard met het herkennen en waarderen van bijzondere prestaties. In termen van het 'ui-model' kunnen excellente prestaties gepaard gaan met 'rituelen', zoals ceremonies bij diplomauitreikingen en de opening van het academisch jaar, of worden gewaardeerd in de vorm van 'symbolen' (bijvoorbeeld prijzen of medailles). Individuele waardering van (excellente) prestaties is echter binnen het onderwijs niet vanzelfsprekend. Hofstede, Hofstede en Minkov (2011) benoemen culturele drempels voor het uiten van waardering voor excellente prestaties. Zo past waardering voor uitmuntende prestaties beter binnen een individualistische cultuur waarin het individu zich mag onderscheiden, zoals in de Verenigde Staten, dan in een collectivistische cultuur. Pogingen om uit te blinken worden in een masculiene cultuur meer gewaardeerd dan in een feminiene cultuur. "In feminiene culturen prijzen docenten eerder zwakke leerlingen, om ze aan te moedigen, dan goede. Onderscheidingen voor excellente prestaties, voor leerlingen of ook voor docenten, zijn in deze culturen niet populair; excellent is een masculien woord" (Hofstede, Hofstede, \& Minkov, 2011, p. 166).

\section{Cultuurverandering binnen het hoger onderwijs}

Is een cultuur te veranderen? Veelal wordt belang gehecht aan leiderschap en de rol van het management (Boonstra, 2011; Kane-Urrabazo, 2006; O’Reilly, 1989). Hofstede, Hofstede en Minkov (2011) geven aan dat het veranderen van een organisatiecultuur een proces is van lange adem; een taak voor het topmanagement die niet kan worden gedelegeerd. Het begint met een cultuurdiagnose en de vraag welke cultuurverandering nodig en haalbaar is. Het management formuleert vervolgens de stappen die nodig zijn voor cultuurverandering. Van belang is daarbij een netwerk van medestanders te creëren, de noodzakelijke veranderingen te ontwerpen, het personeelsbeleid te herzien en de veranderingen in de organisatiecultuur te volgen. Pelletier, Séquin-Lévesque en Legault (2002) wijzen erop dat het van bovenaf druk uitoefenen ter bevordering van een ambitieuze studiecultuur, bijvoorbeeld door invoering van verplichtingen of nadruk op hogere cijfers, juist het tegendeel kan teweegbrengen omdat intrinsiek gemotiveerde 
docenten ontmoedigd worden en vervolgens studenten minder uitdagend onderwijs bieden.

Waarden ontwikkelen zich binnen socialisatie- en opvoedingsprocessen waarin men opgroeit. Pascarella en Terenzini (2005) beschrijven diverse studies die aantonen dat ook het hoger onderwijs nog invloed heeft op de ontwikkeling van waarden en houdingen van studenten, bijvoorbeeld op het gebied van etnische gelijkwaardigheid of op de morele ontwikkeling van studenten. Bepaalde factoren, zoals de campussituatie of de context van kleine, private liberal arts colleges, kunnen dit effect versterken (Pascarella \& Terenzini, 2005). Groeps- en leeftijdgenoten (peers) hebben een belangrijke invloed op de mate waarin studenten of leerlingen zich inspannen en volharden om door te zetten in het uiteindelijk behalen van studiesucces. Peers hebben invloed op zowel de ontwikkeling van waarden en houdingen als op studievoortgang en volharding (Eggens, 2011; Pascarella \& Terenzini, 2005). Studenten zoeken identificatie en verbondenheid bij leeftijdgenoten die in belangrijk opzicht op hen lijken en van wie ze denken dat ze hun opvattingen delen (Rinn \& Plucker, 2004). Zowel sociale als academische integratie zijn belangrijk voor het behalen van studiesucces (Tinto, 1987). De culturele achtergrond van een student is medebepalend voor de mate van integratie en de aansluiting bij peers en ook voor de mogelijke afstand tussen 'thuiscultuur' en 'opleidingscultuur'. Van belang is dat docenten kennis hebben van culturele verschillen en sociale processen die zich daarbij voordoen, verschillen waarderen en leren omgaan met divers talent (Severiens, 2010).

\section{Honourscultuur}

De sociale context (community of leergemeenschap) wordt met name in sociaalconstructivistische theorieën gezien als belangrijke factor in het leerproces (bijvoorbeeld Wenger, 1997). Wilson, Ludwig-Hardman, Thornam en Dunlap (2004) wijzen erop dat een leergemeenschap in het leven wordt geroepen door een specifieke cursus of een programma, zoals een honoursprogramma. Door selectie van sterk gemotiveerde en bekwame studenten wordt een aparte (sub)groep gecreëerd met een eigen, ambitieuze cultuur. Onderzoek toont aan dat door honoursprogramma's actieve netwerken worden gevormd van studenten die bijdragen aan de talentontwikkeling (Van Ginkel, Van Eijl, Pilot, \& Zubizarreta, 2012). Zij vormen een leergemeenschap met frequente contacten, een gedeelde passie voor uitdaging en excellentie, gemeenschapsgevoel en een cultuur van excellentie (Van Ginkel, Van Eijl, \& Pilot, 2014). Een manier om excellentie (uitmuntende prestaties) tot stand te brengen is studenten die meer willen en meer kunnen bij elkaar te brengen in een honoursprogramma. Het idee is dat een honourscommunity met een eigen honourscultuur bijdraagt aan cultuurverandering (zie bijvoorbeeld Siriusprogramma, 2013). Er is echter nog relatief weinig onderzoek gedaan naar de kenmerken en uitstralingseffecten van een honourscultuur (De Boer \& Van Eijl 2010; Van Ginkel, Van Eijl, Pilot, \& Zubizarreta, 2012). 
Op basis van literatuur over honoursstudenten en cultuur van honourscommunity's kunnen vier hoofdelementen worden onderscheiden (Tiesinga, 2013a, 2013b):

- gerichtheid op samenwerking: samenwerking met gelijkgezinden, kennisdelen en netwerken;

- gerichtheid op eigen ontwikkeling: intrinsieke motivatie, zelfsturing en reflectie;

- gerichtheid op excellentie: hoge eisen stellen, uitdaging aangaan, streven naar het beste resultaat, taaktoewijding;

- gerichtheid op innovatie: nieuwsgierig, onderzoekend, risico's aangaan, gerichtheid op innovatieve en creatieve oplossingen.

Een honourscommunity wordt veelal gezien als essentieel voor een volledig ontwikkeld honoursprogramma. Studenten ervaren het als stimulerend om met en tussen gemotiveerde en getalenteerde medestudenten te werken. Ze versterken elkaar, ze vormen een studiegroep en ontwikkelen effectieve studiegewoonten (Van Eijl, 2007; Van Ginkel, Van Eijl, Pilot, \& Zubizarreta, 2012;). Het creëren van een community waarin honoursstudenten samenwerken, elkaar feedback geven en actief leren is een van de belangrijkste pijlers van honoursonderwijs (Wolfensberger, 2012).

\section{Gerichtheid op de eigen ontwikkeling}

Studenten in honoursprogramma's beschikken over een sterke intrinsieke motivatie. Honoursstudenten zijn nieuwsgierig en geïnteresseerd en waarderen vrijheid om aan hun ontwikkeling te werken (Wolfensberger \& Offringa, 2012). Er is een samenhang tussen intrinsieke motivatie en de behoefte van studenten aan zelfsturing (zelfregulatie) bij de vormgeving van hun eigen ontwikkeling. Competitie en druk van buitenaf kunnen de intrinsieke motivatie ondermijnen (Ryan \& Deci, 2000). Ook reflectie over het leren is van belang voor zelfregulatie. Zelfregulatie, onafhankelijke motivatie en het toepassen van metacognitieve strategieën hangen nauw met elkaar samen (Zimmerman, 1990). Honoursstudenten hebben daarom vrijheid nodig, ruimte om te experimenteren en open leersituaties die zelfregulatie toelaten (Wolfensberger, 2012).

\section{Gerichtheid op excellentie}

Aan een community van honoursstudenten wordt over het algemeen een positief excellentieklimaat toegeschreven. De cultuur van een honourscommunity wordt ook wel aangeduid als een op excellentie gerichte cultuur met hoge verwachtingen ten aanzien van zichzelf en medestudenten, hard werken en het beste uit jezelf halen (Van Eijl, 2007). Wolfensberger, Pilot, Van der Vaart, Van Eijl, en Tromp (2004) geven aan dat uitdaging en leerplezier vaak voorwaarde zijn voor toelating en voor studenten ook vaak belangrijke redenen voor deelname. Met andere woorden: zij zoeken uitdaging en gaan die uitdaging graag aan. Ze zijn veelal bereid extra tijd te investeren in activiteiten, ook als ze niet met extra studiepunten worden beloond. 


\section{Gerichtheid op innovatie}

Mariz (2008) omschrijft de honourscultuur als een cultuur van intellectuele uitdaging, een onderzoekende houding en bereidheid om harde, kritische vragen te stellen. Slavin (2008) sluit hierbij aan en noemt als belangrijkste cultuurkenmerk het nemen van intellectuele risico's. Intellectuele risico's nemen heeft ook betrekking op anders durven denken, zoeken naar creatieve en innovatieve werkwijzen en oplossingen. Creativiteit is een belangrijk element van excellentie, naast zaken als intelligentie en taaktoewijding (hard werken en volharding) (Renzulli, 1978; Sternberg, 2003). Zoeken naar creatieve en innovatieve oplossingen heeft ook betrekking op: anders durven denken, vanzelfsprekendheden in twijfel durven trekken, problemen anders definiëren, goede vragen stellen, out of the box-denken, risico's durven nemen en kunnen omgaan met onzekerheid (Sternberg, 2003). Sternberg spreekt van de creatieve innovator, die het aandurft om op te staan tegen gevestigde belangen en meningen van de massa.

\section{Onderzoek naar honourscultuur}

\section{Doel en vraagstelling}

Aan de Hanzehogeschool Groningen is door het lectoraat Excellentie in Hoger Onderwijs en Samenleving onderzoek gedaan naar de cultuur van honoursstudenten (Tiesinga, 2013a, 2013b). Het betreft een exploratief onderzoek met behulp van interviews. Doel van de studie was inzicht te krijgen in de cultuur van honourscommunity's, zoals ervaren door honoursstudenten en honoursdocenten. Leidende vragen zijn: wat kenmerkt de cultuur van een community van honoursstudenten; waarin verschilt ze van de reguliere studiecultuur; en wat is de mogelijke invloed van honourscultuur op de reguliere studiecultuur? Meer specifieke onderzoeksvragen waren: welke elementen van honourscultuur worden door honoursstudenten en -docenten verwoord; welke verschillen signaleren honoursstudenten en -docenten tussen honoursstudenten en reguliere studenten; hoe is in de perceptie van honoursstudenten en -docenten de interactie met de omgeving buiten honours; ervaren honoursstudenten een positieve waardering; welke invloed hebben honoursstudenten op reguliere studenten?

\section{Methode}

Het onderzoek bestond uit twee delen, namelijk vijf groepsinterviews met (in totaal achttien) honoursstudenten en tien interviews met individuele honoursdocenten van uiteenlopende opleidingen van de Hanzehogeschool Groningen. Het betreft honoursprogramma's van 30 ECTS die de studenten volgen bovenop het reguliere studieprogramma.

\section{Groepsinterviews met honoursstudenten}

De groepsinterviews werden gehouden op basis van een open interviewschema, met vijf componenten:

1 Individuele waarden: 'wat voor mij belangrijk is';

2 Gedeelde waarden: 'wat we als groep belangrijk vinden'; 
3 De manier van doen in de honoursgroep: gedrag, gewoonten, afspraken binnen de groep;

4 De interactie met de docent(en) in het honoursprogramma;

5 De interactie met de omgeving (opleiding, docenten, andere studenten, ouders, vrienden, werkveld).

De interviews werden uitgevoerd door een vaste interviewer en genotuleerd door een notulist. Na een korte introductie werd studenten gevraagd hun gedachten bij de onderwerpen in het interviewschema individueel, beknopt op 'post-its' te schrijven. Vervolgens werden de 'post-its' op een vel papier geplakt en door studenten toegelicht. Na bespreking werden aanvullende vragen gesteld over de verschillen met reguliere studenten en regulier onderwijs. De interviews werden opgenomen op geluidsrecorder en daarna getranscribeerd. Transcripties werden gecodeerd en geanalyseerd met het programma Atlas.ti. De codering werd door twee personen uitgevoerd op basis van consensus. De codes werden toegekend in bewoordingen die zo dicht mogelijk bij de uitspraken van de studenten lagen. Pas achteraf werden codes, indien mogelijk, gekoppeld aan de vier elementen van honourscultuur die op basis van de literatuur werden onderscheiden. De aanvullende vragen die aan het eind van het interview werden gesteld, werden eveneens gecodeerd.

\section{Interviews met docenten}

In het onderzoek zijn ook tien honoursdocenten individueel geïnterviewd. De docenten werden at random geselecteerd uit een niet-alfabetische lijst van honoursdocenten. De vragenlijst is opgebouwd van open, ruime vragen naar meer gerichte, specifieke vragen. Eerst is gevraagd naar ervaringen en de visie op de rol van de honoursdocent. Daarna is gevraagd naar verschillen tussen honoursstudenten en reguliere studenten, vervolgens naar cultuuraspecten van groepen studenten (honours versus regulier). Aan het eind van het interview is doorgevraagd naar de interactie tussen honoursstudenten en reguliere studenten, om zicht te krijgen op de vraag of er sprake is van een stimulerende invloed van honoursstudenten op reguliere studenten of eerder van botsende culturen. De interviews werden op geluidsrecorder opgenomen en vervolgens getranscribeerd. Transcripties werden naderhand samengevat, geordend volgens de vragen in de vragenlijst (zie Tiesinga, 2013a).

\section{Resultaten}

Kwantitatieve analyse groepsinterviews studenten

In de onderstaande tabellen is het aantal uitspraken weergegeven. De gegevens werden geordend op basis van de vier cultuurelementen van honourscultuur waarin de uitspraak kadert. Daarnaast wordt aangegeven in welke geïnterviewde groep de uitspraak werd gedaan. Dit geeft een beeld van de mate waarin de verschillende elementen in de afzonderlijke groepen aan de orde kwamen. 
Tabel 1

Studentuitspraken over honourscultuur - aantallen gecodeerde uitspraken in studenteninterviews

\begin{tabular}{|c|c|c|c|c|c|}
\hline $\begin{array}{l}\text { Hoofdelemen- } \\
\text { ten honours } \\
\text { community }\end{array}$ & $\begin{array}{r}\text { Vastgoed } \\
\text { \& Make- } \\
\text { laardij }\end{array}$ & $\begin{array}{l}\text { Rechten- } \\
\text { studies }\end{array}$ & $\begin{array}{r}\text { Sportstu- } \\
\text { dies }\end{array}$ & $\begin{array}{r}\text { Toegepaste } \\
\text { Psycholo- } \\
\text { gie }\end{array}$ & $\begin{array}{c}\text { Lifescience Totaal } \\
\text { \& Techno- } \\
\text { logy }\end{array}$ \\
\hline $\begin{array}{l}\text { Eigen ontwikke- } \\
\text { ling }\end{array}$ & 15 & 10 & 8 & 19 & $136522 \%$ \\
\hline Samenwerking & 22 & 34 & 34 & 29 & $1413346 \%$ \\
\hline $\begin{array}{l}\text { Innovatie/creativi- } \\
\text { teit }\end{array}$ & 7 & 8 & 1 & 0 & $3196 \%$ \\
\hline Excellentie & 9 & 15 & 16 & 5 & 247 I6\% \\
\hline Overige & 6 & 4 & 2 & 6 & $102810 \%$ \\
\hline Totaal & 59 & 7I & 61 & 59 & $42 \quad 292$ \\
\hline
\end{tabular}

Uit tabel 1 blijkt dat circa 90\% van de gecodeerde uitspraken inpasbaar is binnen de vier hoofdelementen; $10 \%$ valt binnen de categorie 'overige'.

De getallen geven aan welke elementen spontaan door de studenten werden benoemd, op basis van het open interviewschema. Zoals zichtbaar wordt in tabel 1, passen de meeste uitspraken van de studenten binnen het cultuurelement 'samenwerking' en vervolgens binnen 'eigen ontwikkeling'. Minder sterk, maar wel aanwezig, is het element 'excellentie'. Zwak aanwezig is het element 'innovatie/creativiteit'. Dat betekent niet per se dat dit element onbelangrijk is, maar dat studenten uit zichzelf dit element minder gauw benoemen.

\section{Kwalitatieve resultaten uit interviews met studenten en docenten}

Hoewel de interviews met studenten en docenten verschilden in opzet, zijn wel soortgelijke onderwerpen aan de orde gesteld. In tabel 2 zijn de samenvattingen van de antwoorden van studenten en docenten in de interviews (Tiesinga, 2013a) op een aantal hoofdonderwerpen naast elkaar gezet. Het betreft de vier elementen van honourscultuur, verschillen tussen honoursstudenten en reguliere studenten en de interactie met de omgeving buiten honours.

\section{Tabel 2 Samenvatting van antwoorden van studenten en docenten}

\section{Elementen van honourscultuur}

Gerichtheid op eigen ontwikkeling: intrinsieke motivatie, zelfsturing en reflectie

Studenten

Honoursstudenten zijn sterk gemotiveerd en ambitieus en hebben plezier in het leren. Ze hechten grote waarde aan de vrijheid die het honoursprogramma hun biedt om de activiteiten te doen die bij hun ambities en interesse passen en aan de vrijheid om de dingen op hun hun toekomstige professionele leven.
eigen manier te doen.

\section{Docenten}

Honoursstudenten hebben een groot vermogen om te reflecteren op wat ze hebben gedaan, ze bepalen zelf wat ze gaan doen, ze nemen hun kennisontwikkeling in eigen hand, ze komen met thema's die gelieerd zijn aan 
Gerichtheid op samenwerking: samenwerking met gelijkgezinden, kennisdelen en netwerken

Studenten

Honoursstudenten waarderen de onderlinge samenwerking. Er zijn veel aspecten waarin de studenten een hoge mate van gelijkgezindheid ervaren en die de goede samenwerking stimuleren. Een zelfde interesse, motivatie, gerichtheid op kwaliteit en bereidheid om elkaar te helpen. Goede communicatie, goede sfeer en samenwerking vinden de studenten belangrijk. Communicatie en samenwerking zijn in de beleving van de studenten doorgaans goed. Daarbij komen diverse waarden naar voren: eerlijkheid, betrouwbaarheid (je aan afspraken houden), betrokkenheid en respect. Ook kritisch zijn naar elkaar wordt gewaardeerd, maar een te kritische houding kan anderen ook onzeker maken en terughoudendheid tot gevolg hebben. Kennis delen en samen leren wordt gewaardeerd. Daarbij hoort ook het netwerken met docenten, mensen uit het werkveld en alumni.

\section{Docenten}

Honoursstudenten zijn opener naar elkaar toe, beter aan te spreken op wederzijdse verplichtingen en tekortkomingen, ze kunnen beter feedback geven en incasseren, ze durven de waarheid te vertellen, ze stimuleren elkaar, ze willen van elkaar leren over de andere vakgebieden, ze willen graag samenwerken, ze opereren snel als een team, dragen allemaal een steentje bij en doen er moeite voor, ze zoeken elkaar overal/steeds op, stellen een ander type vragen, ze trekken minder maar 'brengen', geven goede presentaties, tonen volwassenheid in optreden, ze worden handig in hun planning. Ze werken goed samen doordat ze allemaal hetzelfde niveau hebben, er is een goede chemie tussen studenten, ze zijn echt belangstellend naar elkaar, ze helpen elkaar, geven elkaar tips, ze denken mee, ze delen hun interesse voor de opleiding met elkaar, er is groepsgevoel. Voor sommigen is het hun thuisbasis, het is niet alleen gezellig, er gebeurt ook iets. Ze zitten dichter tegen de docenten aan, lopen gemakkelijk naar binnen.

Gerichtheid op excellentie: hoge eisen stellen, uitdaging aangaan, streven naar het beste resultaat, taaktoewijding

\section{Studenten}

De gerichtheid op excellentie komt aan bod in termen van gerichtheid op kwaliteit en professionaliteit, uitdaging zoeken, jezelf onderscheiden van de andere studenten en profileren naar het werkveld. Er is sprake van hard werken, zonder daarover te klagen. Wel is het nodig om prioriteiten te leggen om alles te kunnen bolwerken.

\section{Docenten}

Ze willen er iets moois van maken, ze willen meer, jagen elkaar op in hun ambitie, nemen zelf initiatief, ze bepalen zelf wat ze willen, ze vinden het vak leuk en interessant, ze bespreken de boeken serieus met elkaar.

Gerichtheid op innovatie: nieuwsgierig, onderzoekend, risico's aangaan, gerichtheid op innovatieve en creatieve oplossingen

\section{Studenten}

Gerichtheid op innovatie en creativiteit wordt genoemd, maar speelde in de interviews een geringe rol. Per opleiding zijn er verschillen in de manier waarop dit element wordt beleefd. Studenten Vastgoed \& Makelaardij waarderen het procesgerichte, onderzoekend leren; studenten Rechtenstudies noemen creativiteit en out of the box-denken als belangrijk, maar onderzoek lijkt enigszins opgelegd door het programma.

\section{Docenten}

Ze zijn leergierig, ze zijn kritischer, er is meer interactie, de interactie is uitdagender, ze zijn creatief, ze gaan met elkaar in discussie 
Als onderscheidende kenmerken van honoursstudenten worden genoemd: nieuwsgierigheid, veel vragen stellen, leergierigheid, kritische instelling, beter met onzekerheden kunnen omgaan, minder bang om fouten te maken (zie hierna).

\section{Verschillen tussen honoursstudenten en reguliere studenten}

\section{Studenten}

Honoursstudenten benoemen als verschil met reguliere studenten vooral motivatie en ambitie en de passie om jezelf te ontwikkelen, op grond van zelfsturing en reflectie. Hiermee hangt ook samen de mate van toekomstgerichtheid van honoursstudenten, op grond waarvan ze bewustere keuzes maken binnen de studie. Een voorwaarde voor het zelf vormgeven van de eigen ontwikkeling is volgens de studenten dat je een grote mate van vrijheid aan moet kunnen.

\section{Interactie met de omgeving}

\section{Studenten}

De reacties van reguliere medestudenten zijn in de beleving van honoursstudenten vaak negatief; honoursstudenten zijn bang dat ze als strebers of als elitegroepje worden gezien; ze voelen zich daardoor geremd om zich als honoursstudent te profileren en zijn dan geneigd zich 'nonchalanter' voor te doen dan ze eigenlijk zijn.

Vooral docenten hebben vaak hoge verwachtingen van het gedrag en de prestaties van honoursstudenten. Het werkveld reageert doorgaans positief; ook hier spelen hoge verwachtingen een rol.

Ouders en familie kunnen verschillend reageren; vrienden reageren doorgaans positief.

\section{Docenten}

\section{Verschil in motivatie en gedrevenheid:}

Meer motivatie en ambitie, gedreven, eager, intrinsiek gemotiveerd met betrekking tot de studie, niet bang voor extra werk; ze willen graag scoren.

\section{Verschil in denken en doen:}

Hoger abstractieniveau, nieuwsgierig, veel vragen stellen, leergierig, goed voorbereid, kritisch, ze stimuleren elkaar; een bredere kijk; proactiever, minder bang om fouten te maken.

\section{Verschil in rijping, zelfsturing en toekomst-} gerichtheid:

Ouder, volwassener, meer toekomstgericht, weten waar ze naartoe willen, koppeling aan arbeidsperspectief, eigenzinnig; ze nemen zelf verantwoordelijkheid voor hun leerproces, hun eigen ontwikkeling, voor anderen; ze kunnen beter omgaan met onzekerheid.

\section{Docenten}

De honoursdocenten hebben weinig zicht op de manier waarop reguliere studenten reageren op het honoursprogramma en de honoursstudenten. De docenten merken dat sommige studenten worstelen met de hoge verwachtingen die er bestaan. Daarnaast is er soms sprake van stigmatisering: honoursstudenten die als strebers of uitslovers worden bestempeld. Sommige docenten geven aan dat er weinig belangstelling is van medestudenten voor de activiteiten van honoursstudenten. Dat blijkt uit de lage opkomst wanneer honoursstudenten hun activiteiten presenteren voor reguliere studenten.

\section{Conclusies}

In deze paragraaf gaan we in op de drie centrale vragen die voor dit artikel werden geformuleerd: wat kenmerkt de cultuur van honoursstudenten; waarin verschilt 
deze van de reguliere studiecultuur; en wat is de mogelijke invloed van honourscultuur op de reguliere studiecultuur?

\section{Kenmerken van honourscultuur}

De eerste vraag was: wat kenmerkt de cultuur van honoursstudenten? Het onderzoek bevestigt het bestaan van een eigen subcultuur van honoursstudenten. Vooral aspecten die te maken hebben met de gerichtheid op eigen ontwikkeling en op samenwerking worden door zowel honoursstudenten als honoursdocenten vaak genoemd. De elementen die verband houden met de gerichtheid op excellentie en innovatie worden minder vaak spontaan benoemd. Enig voorbehoud ten aanzien van de resultaten is enerzijds geboden: het onderzoek is kleinschalig en beperkt zich tot de Hanzehogeschool Groningen. Anderzijds zijn de uitkomsten in lijn met de literatuur over honoursstudenten en honoursonderwijs en was er een sterke mate van eenduidigheid binnen groepen studenten, tussen groepen en tussen studenten en docenten.

Het bij elkaar brengen van honoursstudenten brengt een dynamiek op gang die door honoursstudenten en honoursdocenten als stimulerend wordt ervaren. Docenten geven aan dat verdere stimulans door docenten nauwelijks nodig is, omdat studenten elkaar opjagen in hun ambities en elkaar stimuleren tot excellente prestaties. Die gedrevenheid kenmerkt de cultuur van een community van honoursstudenten. Een praktische implicatie is dat de vorming van een community van honoursstudenten meerwaarde biedt boven een puur individuele opzet.

\section{Cultuurverschillen}

Waarin verschilt de cultuur van honoursstudenten met de reguliere studiecultuur? Zowel honoursstudenten als honoursdocenten benoemen verschillen met de reguliere studenten, vooral met betrekking tot motivatie en ambitie, zelfsturing en reflectie, rijping en toekomstgerichtheid, verschillen in denken en doen. In termen van gedrag komen kenmerken naar voren als: ze stimuleren elkaar, bereiden zich goed voor, zijn proactief, tonen zich verantwoordelijk, werken goed samen. Onderzoek van Scager et al. (2012) toont aan dat honours- en niethonoursstudenten op een aantal kenmerken van elkaar verschillen, vooral in de wil om te leren, de behoefte om te excelleren en de mate van creatief denken. Kenmerken die sterk overeenkomen met drie van de vier elementen van honourscultuur die hiervoor op basis van theorie en binnen het onderzoek van de Hanzehogeschool werden onderscheiden: gerichtheid op eigen ontwikkeling, excellentie en innovatie/creativiteit. Het vierde element, samenwerking tussen studenten, maakte (als variabele binnen de leeromgeving) geen deel uit van het onderzoek van Scager.

Dat er sprake is van cultuurverschillen blijkt ook uit de interviews met studenten en docenten. Honoursstudenten ervaren soms een gebrek aan interesse of zelfs weerstand bij de reguliere groep van medestudenten en zijn niet altijd geneigd om als zichtbaar rolmodel naar voren te treden. 


\section{Mogelijke invloed op de reguliere studiecultuur}

Wat is de mogelijke invloed van honourscultuur op de reguliere studiecultuur? We bespreken de onderzoeksresultaten in samenhang met een publicatie van Harris (1998), die aangeeft onder welke voorwaarden sprake kan zijn van beïnvloeding van een dominante (reguliere) cultuur door een subcultuur binnen een bedrijf. De voorwaarden die hij noemt, zijn wellicht ook toepasbaar binnen de context van het hoger onderwijs.

De eerste voorwaarde is dat er sprake is van een duidelijk identificeerbare, zichtbare subgroep met een sterke cultuur. Aan deze voorwaarde lijkt op grond van de literatuur en de onderzoeksresultaten een honourscommunity te kunnen voldoen. De cultuur van honoursstudenten lijkt een stimulans te kunnen bieden voor cultuurverandering naar een meer ambitieuze studiecultuur, waarbij honoursstudenten als rolmodel kunnen fungeren. Omdat studenten beïnvloed worden door medestudenten is het denkbaar dat de subcultuur van honoursstudenten een positieve invloed heeft op de studiecultuur van de reguliere studenten. Wellicht kan door honoursprogramma's een netwerk van medestanders (honoursstudenten én honoursdocenten) worden gecreëerd voor cultuurverandering. Uit de interviews blijkt echter dat studenten zich geremd kunnen voelen om naar buiten toe ambitie en uitmuntende prestaties te tonen en om zich te manifesteren als honoursstudent. Juist voor de positieve uitstraling, waarbij honoursstudenten als rolmodel kunnen fungeren voor anderen, is die zichtbaarheid van belang. Daarom is het belangrijk dat studenten leren hoe ze hun ambities en activiteiten kunnen presenteren zonder dat dit weerstand oproept bij anderen.

Voor de beïnvloeding van de dominante cultuur moet volgens Harris (1998) de reguliere groep ontvankelijk zijn voor verandering en dus geneigd zijn om de gerichtheid op excellentie en ambitie over te nemen in houding en gedrag. Hoe meer de waarden van de subcultuur aansluiten bij de diepere lagen van de reguliere cultuur, des te gemakkelijker zullen deze worden overgenomen. Een deel van de studenten zal mogelijk meer belang hechten aan andere waarden, bijvoorbeeld sociale contacten, ontspanning, of excellentie op een ander terrein dan de studie. Voor zover de verschillen te groot zijn, zullen er weerstanden bestaan of zullen reguliere studenten weinig belangstelling tonen voor de prestaties van honoursstudenten en de roep van de opleiding om meer ambitie te tonen binnen de studie. Onderzoek is nodig om meer inzicht te verkrijgen in de perceptie van de reguliere studenten op excelleren binnen hun opleiding en op hun collega-honoursstudenten.

Een volgende voorwaarde is dat de cultuuraspecten vatbaar zijn voor verandering en overdraagbaar zijn. De studiecultuur van honoursstudenten wordt mede bepaald door kenmerken van studenten, zoals toewijding en motivatie, behoefte aan zelfsturing, gerichtheid op excelleren en creativiteit. Voor zover het kenmerken betreft die sterk verbonden zijn met de persoon, zijn ze moeilijk overdraagbaar. Het gaat hierbij echter om graduele verschillen: de kenmerken zijn wellicht in mindere mate aanwezig, maar niet afwezig bij een grotere groep. 
Verschillende variabelen kunnen een rol spelen bij de uitstralingseffecten van honoursprogramma's, bijvoorbeeld de omvang en de zichtbaarheid van de groep van honoursstudenten. Zichtbaarheid is een eerste voorwaarde. Het verschil tussen honours- en reguliere studenten betekent dat er grenzen zijn aan de mogelijke invloed van een honourscommunity. Ook institutionele variabelen binnen de opleiding, zoals leiderschap en culturele achtergrond van studenten en docenten zullen een rol spelen. Verder onderzoek is gewenst om na te gaan of de subcultuur van honoursstudenten inderdaad uitstraling heeft op de reguliere studiecultuur, onder welke voorwaarden en welke variabelen bij cultuurverandering in het hoger onderwijs een rol spelen.

\section{Referenties}

Boonstra, J. (2011). Leiders in cultuurverandering. Hoe Nederlandse organisaties succesvol hun cultuur veranderen en strategische vernieuwingen realiseren. Assen: Van Gorcum.

Bower, M. (1966). Will to manage. New York: McGraw-Hill.

Deal, T.E., \& Kennedy, A.A. (1982). Corporate cultures: The rites and rituals of corporate life. Reading, M.A.: Addison-Wesley.

Deal, T.E., \& Peterson, K.D. (2009). Shaping School Culture. Pitfalls, Paradoxes, \& Promises. San Francisco: John Wiley \& Sons/ Jossey-Bass.

De Boer, D., \& Van Eijl, P. (2010). Naar een onderzoeksagenda voor talentontwikkeling in het hoger onderwijs. Tijdschrift voor Hoger Onderwijs, 28(4), 239-250.

Eggens, L. (2011). The Student X-Factor: Social and Psychological Determinants of Students' Attainment in Higher Education. Groningen: Rijksuniversiteit Groningen.

Harris, L.C. (1998). Cultural domination: the key to market-oriented culture? European Journal of Marketing, 32, 354-373.

Harris, L.C., \& Ogbanna, E. (1999). Developing a Market Oriented Culture: a Critical Evaluation. Journal of Management Studies, 36(2), 177-196.

Hofstede, G., Hofstede, G.J., \& Minkov, M. (2011). Allemaal andersdenkenden. Omgaan met cultuurverschillen. Amsterdam: Uitgeverij Contact.

Hudley, C., \& Daoud, A.M. (2008). Cultures in contrast. Understanding the influence of school on student engagement. In C. Hudley \& A.E. Gottfried (eds.), Academic motivation and the culture of school in childhood and adolescence (pp. 1-32). New York: Oxford University Press. Geraadpleegd via http://oxfordscholarship.com.

Kane-Urrabazo, C. (2006). Management's role in shaping organizational culture. Journal of Nursing Management, 14, 188-194.

Mariz, G. (2008). The Culture of Honors. Journal of the National Collegiate Honors Council, 9(1), 19-25.

Martin, J. (2004). Organizational Culture. Research Paper No 1847. Research Paper Series. Stanford: Graduate school of Business.

Ministerie van OCW (2007). Strategische agenda voor het hoger onderwijs-, onderzoek- en wetenschapsbeleid. Den Haag: Ministerie van OCW.

Ministerie van OCW (2011). Kwaliteit in verscheidenheid. Strategische Agenda Hoger Onderwijs, Onderzoek en Wetenschap. Den Haag: Ministerie van OCW.

O'Reilly, Ch. (1989). Corporations, Culture, and Commitment: Motivation and Social Control in Organizations. California Management Review, 31, 9-25.

Pascarella, E.T., \& Terenzini, P.T. (2005). How College Affects Students. Volume 2. A Third Decade of Research. San Francisco: Jossey-Bass. 
Pelletier, L.G., Séguin-Lévesque, Ch., \& Legault, L. (2002). Pressure From Above and Pressure From Below as Determinants of Teachers' Motivation and Teaching Behaviors. Journal of Educational Psychology, 94, 186-196.

Postareff, L., Lindblom-Ylänne, S., \& Nevgi, A. (2007). The effect of pedagogical training on teaching in higher education. Teaching and Teacher Education, 23, 557-571.

Renzulli, J.S. (1978). What makes giftedness? Reexamining a definition. Phi Delta Kappan, 60, 180-184.

Rinn, A.N., \& Plucker, J.A. (2004). We recruit them, but then what? The educational and psychological experiences of academically talented undergraduates. Gifted Child Quarterly, 48, 54-67.

Ryan, R.M., \& Deci, E.L. (2000). Intrinsic and Extrinsic Motivations: Classic Definitions and New Directions. Contemporary Educational Psychology, 25, 54-67.

Sanders, G., \& Neuijen, B. (1999). Bedrijfscultuur: diagnose en beïnvloeding. Assen: Van Gorcum.

Scager, K., Akkerman, S.F., Keesen, F., Mainhard, M.T., Pilot, A., \& Wubbels, T. (2012). Do honors students have more potential for excellence in their professional lives? Higher Education, 64, 19-39.

Severiens, S. (2010). Divers talent in de klas. Rotterdam: Risbo, Erasmus Universiteit.

Siriusprogramma (2013). Op koers met excellentie. Den Haag: Siriusprogramma.

Slavin, Ch. (2008). Defining Honors Culture. Journal of the National Collegiate Honors Council, 9 (1), 15-18.

Sternberg, R.J. (2003). WICS as a model of giftedness. High ability studies, 14, 109-139.

Stes, A., Coertjens, L., \& Van Petegem, P. (2010). Instructional development for teachers in higher education: impact on teaching approach. Higher education, 60, 187-204

Tiesinga, L. (2013a). Cultuur van honourscommunities. Rapportage Onderzoek excellentie, communities en cultuur. Groningen: Hanzehogeschool Groningen. Geraadpleegd via http:// www.hanze.nl/excellentie.

Tiesinga, L. (2013b). Student en docent in een honourscultuur. In R. Coppoolse, P. van Eijl \& A. Pilot (red.), Hoogvliegers; ontwikkeling naar professionele excellentie (pp. 177-194). Rotterdam: University Press, Hogeschool van Rotterdam.

Tinto, V. (1987). Leaving college: Rethinking the causes and cures of student attrition. Chicago: University of Chicago Press.

Van Eijl, P.J. (2007). Honours, tool for promoting excellence. Eindrapport van het project 'Talentontwikkeling in Honoursprogramma's en de meerwaarde die dat oplevert'. IVLOSMededeling $n r$. 82. Utrecht: Universiteit Utrecht.

Van Ginkel, S., Van Eijl, P., \& Pilot, A. (2014). De honourscommunity: kenmerken, functies en strategieën. Tijdschrift voor Hoger Onderwijs, 31/32 (4/1), 20-36.

Van Ginkel, S., Van Eijl, P., Pilot, A., \& Zubizarreta, J. (2012). Building a vibrant honors community among commuter students. Journal of the National Collegiate Honors Council, 13(2), 197-218

Wenger, E. (1997). Communities of practice: Learning, meaning and identity. Cambridge: Cambridge University Press.

Wilson, B.B., Ludwig-Hardman, S., Thornam, C.L., \& Dunlap, J.C. (2004). Bounded Community: Designing and Facilitating Learning Communities in Formal Courses. The International Review of Research in Open and Distance Learning, 5 (3), 1-22.

Wolfensberger, M.V.C., Pilot, A., Van der Vaart, R.J., Van Eijl, P.J., \& Tromp, S. (2004). Paper gepresenteerd op de Onderwijs Research Dagen juni 2004: Studenten in Honours Programmes: Hun kenmerken en concepties van universitair onderwijs. Een pilotstudie. Utrecht: Universiteit Utrecht. 
Wolfensberger, M.V.C. (2012). Teaching for Excellence. Honors Pedagogies Revealed. Münster: Waxmann.

Wolfensberger, M.V.C., \& Offringa, G.J. (2012). Qualities honours students look for in Faculty and Courses, Revisited. Journal of the National Collegiate Honors Council, 13(2), 171-182.

Zimmerman, B.J. (1990). Self-Regulated Learning and Academic Achievement: An Overview. Educational Psychologist, 25(1), 3-37. 